\title{
Progressive right lower extremity enlargement
}

\author{
Scott Tyson • Aaron Wyse • Naveen Subhas • \\ Murali Sundaram
}

Published online: 20 October 2011

(C) Springer-Verlag 2011

\section{Question:}

A 72-year-old female with a history of lymphedema, type II diabetes mellitus, and adult onset dermatomyositis (diag- nosed at age 64) presented for evaluation of progressive lower extremity weakness and progressive enlargement of her right lower extremity. The patient described her leg weakness as chronic, however the right leg enlargement had
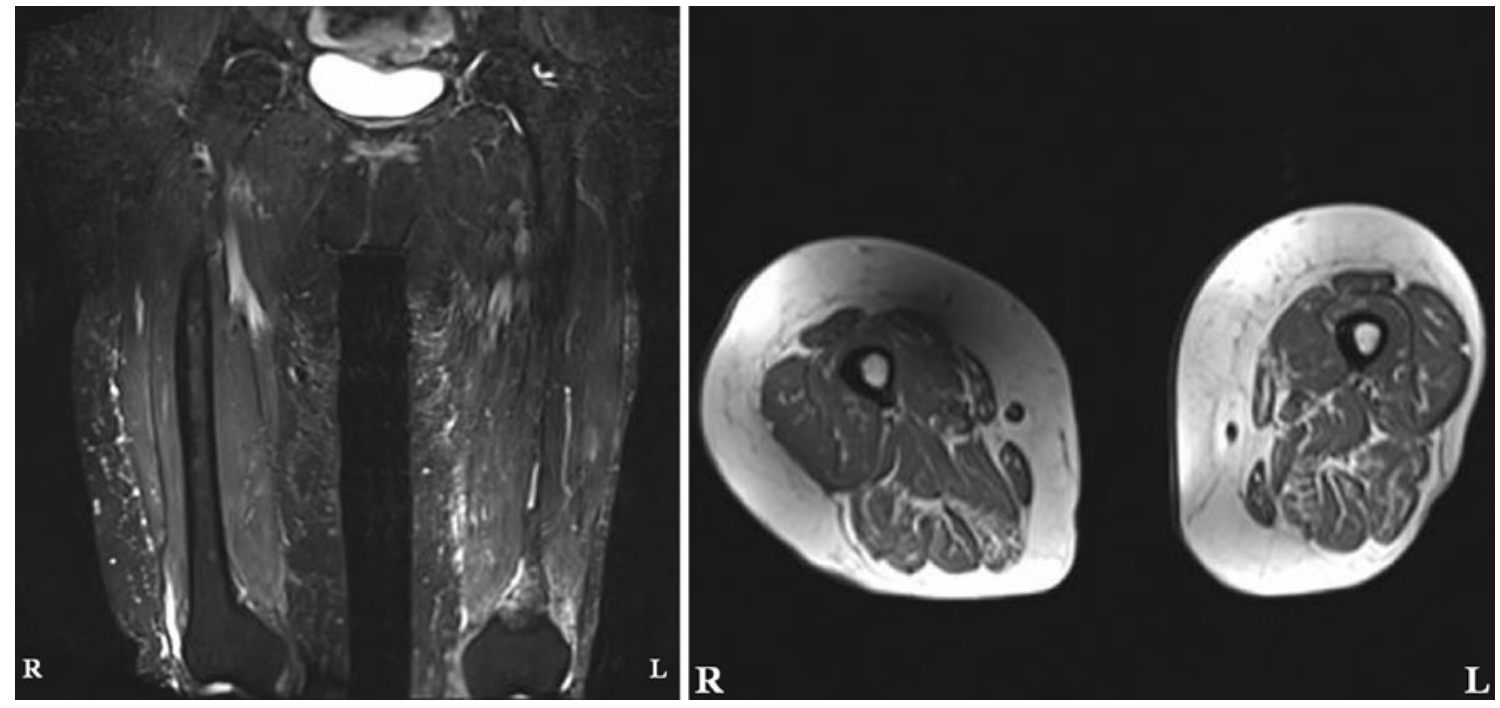

Fig. 1 Coronal STIR and axial T1 images of the femur

The diagnosis can be found at doi:10.1007/s00256-011-1279-z.

S. Tyson $(\bowtie) \cdot$ A. Wyse $\cdot$ N. Subhas $\cdot$ M. Sundaram Cleveland Clinic Imaging Institute,

9500 Euclid Ave. Hb6,

Cleveland, OH 44195, USA

e-mail: tysons@ccf.org 

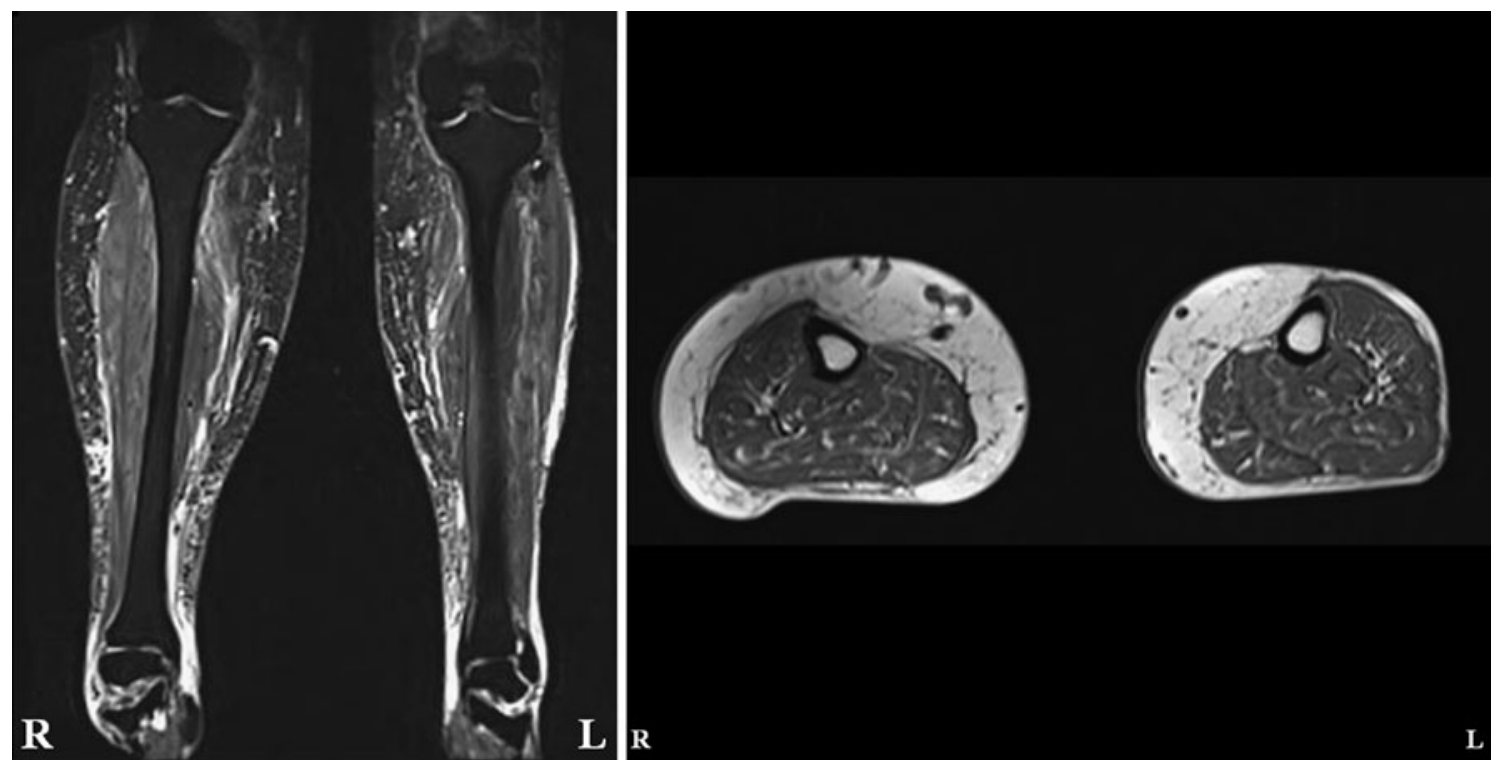

Fig. 2 Coronal STIR and axial T1 images of the tibia

been progressive over the last 12 months. The patient had previously been prescribed furosemide and compression stockings to be worn on her right leg, but these were ineffective. The patient was referred to our institution for further evaluation, and an MRI of the lower extremities was performed (Figs. 1 and 2).

Conflict of interest The authors declare they have no conflict of interest. 